\title{
Interação cuidador familiar-pessoa com AVC: autonomia compartilhada
}

\author{
Interaction between stroke survivors \\ and family caregivers: shared autonomy
}

Sílvia Cristina Mangini Bocchi 1

$\mathrm{M}$ argareth Angelo 2

\footnotetext{
1 Departamento de Enfermagem, Faculdade de M edicina de Botucatu/Unesp. Distrito de Rubião Júnior, 18618-970, Botucatu SP. sbocchi@fmb.unesp.br 2 Departamento de Enfermagem $M$ aternoInfantil e Psiquiatria. Escola de Enfermagem/USP.
}

A bstract This paper is a qualitative study using the Grounded Theory as a methodological reference and the Symbolic Interactionism as a theoretical reference. It aimed at understanding the family caregiver's experience with stroke survivors on the care systems adopted by them during the home rehabilitation process, as it follows: - encouraging the patient's autonomy recovering and - not encouraging the patient's autonomy. As the components towards the experience have been interrelated, it could be observed that the own care giver has perceived that the process of autonomy recovering either that of the CVA-patient or his own have been interdependent and related to the rehabilitation level reached by the patient.

Key words Cerebrovascular accident, Patient, Family, Rehabilitation
Resumo Trata-se de um estudo qualitativo, utilizando-se como referencial metodológico a Grounded Theory e como referencial teórico o I nteracionismo Simbólico, para compreender a experiência de cuidadores familiares de pessoas com AVC, acerca das modalidades de cuidado adotadas por eles, durante o processo de reabilitação de uma pessoa com AVC no domićlío. Tais modalidades podem ser exercidas: incentivando o doente a recuperar a sua autonomia; e não estimulando a autonomia do doente. Ao inter-relacionar os componentes relativos à experiência, evidenciamos que o próprio cuidador familiar percebe que os processos de retomada da autonomia - da pessoa vitimada pelo AVC e de sua própria - se configuram como interdependentes e condicionados ao nível de reabilitação alcançado pelo doente. Palavras-chave Acidente cerebrovascular, $\mathrm{Pa}$ ciente, Família, Reabilitação 


\section{Introdução}

O Acidente Vascular Cerebral (AVC), a partir de 1996, vem se constituindo, na população brasileira, como causa principal de internações, mortalidade e deficiências, acometendo a faixa etária acima de 50 anos, superando até mesmo as doenças cardíacas e o câncer (M inistério da Saúde, 2000). I sto não acontece em países industrializados, já que estas doenças permanecem como as duas primeiras causas de mortes (Ragland, 1998), sendo o AVC a terceira e em processo de declínio em alguns deles (Ellekjaer et al. 1997), enquanto outros, que já passaram por esta fase, vivenciam um momento de estabilização (Reistma et al., 1998).

O Brasil, desde a década de 1940, vem passando por um processo de inversão das curvas de mortalidade, observando-se um declínio de mortes por doenças infecciosas e um concomitante aumento por doenças crônicas não-transmissíveis e causas externas. Este processo é conhecido por fenômeno de transição epidemiológica, ocorrida em todos os países hoje desenvolvidos, nos quais a população de idosos é cada vez mais expressiva (M inistério da Saúde, 2000).

Estima-se que, em hospitais brasileiros, aproximadamente $10 \%$ das internações no ano de 1996 foram por doenças do aparelho circulatório, sendo responsáveis por 17,2\% dos gastos (M inistério da Saúde, 2000).

M esmo quando não são mortais, essas doenças levam com freqüência a deficiências parcial ou total do indivíduo, com graves repercussões para ele, sua família e a sociedade. Isto mostra que 0 investimento na prevenção destas doenças é decisivo, não só para garantir a qualidade de vida aos indivíduos e seus familiares, mas também para se evitarem gastos com a hospitalização, que se torna mais onerosa a cada dia, em razão do alto grau de sofisticação em que se encontra a medicina moderna ( $M$ inistério da Saúde, 2000).

Embora as doenças físicas possam assumir uma variedade de formas, é no âmbito familiar que cada vez mais elas serão resolvidas; por isso os profissionais precisam se instrumentalizar para adquirir uma visão crítica para o oferecimento de uma assistência de qualidade.

Vários autores reforçam o papel vital da família em determinar os resultados da reabilitação do paciente (Griffin, 1980; M auss-Clum \& Ryan, 1981; Reeber, 1992). No entanto, Youngblood \& Hines (1992) complementam que a presença de deficiências físicas severas em um indivíduo cria uma crise não só para a família, mas para ele também. U ma deficiência é uma condição que requer períodos longos de supervisão, observação e cuidado. Por causa das necessidades em longo prazo, a pessoa deficiente, freqüentemente, depende dos membros da família para o cuidado físico, contatos sociais, apoio emocional e ajuda financeira. 0 grau de recuperação pode depender da habilidade familiar em oferecer apoio ao portador dessas deficiências. 0 cuidado e apoio a esta pessoa, freqüentemente, transforma-se em uma sobrecarga significativa para a família.

São essas as razões que nos têm motivado a realizar processos investigatórios sobre a experiência de cuidadores familiares de pessoas com Acidente Vascular Cerebral (AVC), visando ampliar o conhecimento sobre o objeto, como estratégia retroalimentadora do ensino, da pesquisa e da assistência.

O objetivo deste artigo écompreender a experiência de cuidadores familiares brasileiros, com referência às modalidades de cuidado adotadas por eles, durante o processo de reabilitação de uma pessoa com AVC, no domicílio.

\section{Trajetória metodológica}

Este artigo se constitui num recorte, a partir de uma pesquisa mais abrangente acerca da experiência de cuidadores familiares de pessoas com AVC, que resultou em um modelo teórico denominado M ovendo-se entre a liberdade e a reclusão: vivendo uma experiência de poucos prazeres ao vir-a-ser um cuidador familiar de pessoa com AVC (Bocchi, 2001).

Como o relatório final do trabalho se apresentou extenso e por se tratar de um assunto pouco explorado na perspectiva teórico-metodológica adotada, em tempos em que o AVC vem se constituindo na causa principal de internações, mortalidade e incapacidades, o que tem remetido os profissionais da saúde à busca por referenciais norteadores de sua assistência junto das famílias, justifica-se comunicar o conhecimento, por meio de vários artigos. N este, nós apresentaremos o tema que compõe a experiência, relativo às modalidades de cuidado desenvolvidas pelos cuidadores familiares de pessoas com AVC, durante o processo de reabilitação no domićlio.

Trata-se de uma investigação qualitativa, conduzida dentro dos preceitos éticos com fa- 
miliares cuidadores localizados a partir de registros no Centro de Informações M édicas ( $\mathrm{Ci}$ med) de um Hospital Universitário e por meio do Serviço de Fisioterapia de um Hospital Geral, do interior do Estado de São Paulo.

Consideraram-se atores os membros das famílias que se identificavam como familiares cuidadores, por estar assumindo a responsabilidade principal e não-remunerada do cuidado domiciliar de uma pessoa, conforme definição de Grant (1996).

As entrevistas foram realizadas nos próprios domicílios, respeitando a disponibilidade, de forma que os cuidadores respondessem confidencialmente às pesqui sadoras a seguinte questão norteadora: - Como tem sido a sua experiência cuidando de uma pessoa com AVC?

Ao finalizar a gravação de cada entrevista, nós as transcrevemos e as analisamos, de acordo com as etapas do referencial metodológico da Grounded Theory (Glaser \& Strauss, 1967).

A saturação teórica foi obtida mediante a análise da 10a entrevista. Dada a dificuldade que tivemos em localizar homens desempenhando este papel, dos 10 cuidadores familiares, nove eram do sexo feminino e um do masculino. Eles tinham idades entre 36 e 69 anose um tempo como cuidador de três meses a cinco anos. 0 grau de parentesco se distribuiu entre seis cônjuges, duas filhas, uma sogra e uma madrasta, e a renda familiar mensal entre um e mais de 20 salários mínimos.

Tivemos o cuidado em retornar aos domicílios para apresentar o modelo teórico, o qual foi submetido à avaliação dos atores e validado como representativo de suas experiências.

Os resultados foram discutidos à luz do Interacionismo Simbólico, segundo Charon (1989).

\section{Apresentando a experiência}

O tema "Desenvolvendo seu modo de cuidar" será apresentado por meio de conceitos que emergiram, segundo os seus componentes: categorias, subcategorias e elementos. Significa que, ao assumir o cuidado de uma pessoa com AVC, o cuidador familiar procura oferecer 0 melhor de suas possibilidades e crenças. Isto faz emergir na experiência o desenvolvimento de dois modos distintos de cuidar, permeados por meio de duas categorias: 1 ) incentivando 0 doente a recuperar a sua autonomia; e 2) não estimulando a autonomia do doente.

\section{Incentivando o doente a recuperar a sua autonomia}

É o primeiro modo de cuidar, desenvolvido pelo familiar, subsidiado nas suas possibilidades e crença de que ele deve se integrar ao processo de reabilitação do indivíduo, considerando-o sujeito participativo e ativo de sua recuperação. É uma categoria que congrega três subcategorias: a) estimulando o restabelecimento de movimentos; b) reorientando o doente no tempo e no espaço; c) oferecendo outros cuidados que possam ajudar na recuperação.

Estimulando o restabelecimento de movimentos. Significa um conjunto de ações visando estimular a recuperação funcional do doente, comprometida pelo icto e representada pelos elementos: a) mobilizando o doente; b) orientando e auxiliando na deambulação; c) estimulando a se alimentar sozinho.

... para ir ao banheiro eu pego ele assim, levantando e vou levando ele ao banheiro ...

... eu dou um pouco de comida na boca e 0 resto eu incentivo ele a comer ...

Reorientando o doente no tempo e no espaço. Exprime as ações empregadas em experiência de cuidador familiar de pessoa com AVC, com declínio de atividades intelectuais e perceptivas, na tentativa de situá-lo no tempo e no espaço, por meio de conversas, sobre os eventos do cotidiano.

...todos os dias, pela manhã, quando a gente acorda, hojeé dia seis de janeiro de 2000. Hoje é quinta-feira. Ele fala assim: - Nós já estamos no ano 2000? Eu digo que já. (...) Para ele poder se situar. Senão ele fica parado no tempo. Então, tem que estimular o dia todo e essa conversação ... é um estímulo para a mente dele...

Oferecendo outros cuidados que ajudam na recuperação. Representa aquel as ações que contribuirão para uma experiência que promova 0 bem-estar físico e mental do doente eque poderão influenciar na sua recuperação. Elas estão reunidas em três elementos: a) fazendo e oferecendo alimentação de agrado do doente; b) encaminhando e auxiliando o doente na higiene pessoal e eliminações; c) promovendo distrações.

... ele fala: - Dá para sair uma feijoada hoje? Não precisa ser feijoada. É fazer o feijão preto com bacon ea lingüiça e para ele éa maior feijoada ...

... se ele quer sair, eu saio. Eu o coloco no carro evou ... 


\section{Percebendo a recuperação da autonomia do doente}

Significa que, ao incentivar a recuperação do doente, o cuidador familiar começa a notar que está ocorrendo a melhora. As respostas ao seu modo de cuidar são positivas e podem ser agrupadas em duas subcategorias: a) vendo 0 doente começando a se tornar, funcionalmente, independente; $b$ ) percebendo $o$ doente recuperando parte da consciência.

Vendo 0 doente se tornando funcionalmente independente. Significa que o cuidador familiar percebe, na experiência, que o doente está recuperando movimentos de membros afetados com a doença, o que lhe possibilita ir gradativamente reassumindo suas atividades diárias, podendo agora vir a se governar por si só, sem necessidade de ajuda.

... as pernas não governavam mais. A gora melhorou um pouco e ele consegue andar um pouco com a ajuda de uma pessoa ...

Percebendo o doente recuperando parte da consciência. Significa que o cuidador familiar observa, na experiência, que está havendo meIhora no nível de consciência do doente, quando comparado ao início da doença, possibilitando-Ihe recobrar a autonomia.

... porque ele pede tudo, embora o nível de consciência dele não seja normal, mas ele sabe 0 quequer. Quando ele quer ir ao banheiro ...

\section{- Vislumbrando a liberdade}

É uma categoria que exprime o momento em que o cuidador familiar avalia a sua experiência e percebe que há possibilidades de retomar a sua vida anterior ao papel assumido. Esta categoria se compõe de duas subcategorias: a) percebendo a possibilidade de se livrar do papel de cuidador; b) vendo-se em condições de se livrar da enfermagem domiciliar.

Percebendo a possibilidade de se livrar do papel de cuidador. Significa que no continuum da experiência, quando o doente começa a readquirir sua autonomia e, portanto, a ganhar gradativamente a sua independência, reacende no cuidador familiar a possibilidade do vir-a-ser livre de seu papel, para poder retomar as suas atividades, até então abandonadas para assumir o cuidado do doente.

... para comer, você tem que pôr a comida na boca, tem vez que ele pega e come com a mão esquerda. Graças a Deus e isso já é um alívio para a gente... Eu dou um pouco de comida na boca $e$ o resto eu incentivo ele a comer. Ele já está comendo com a mão dele...

...eu fazia caminhada. Eu parei e agora que eu comecei de novo. Porque eu fazia uma hora, uma hora e dez de caminhada todos os dias e agora faz uns quinze dias que eu voltei, porque aí eu vi que ele estava bom e dava para eu ir ...

Vendo-se em condições de se livrar da enfermagem domiciliar. É uma subcategoria que exprime as condições do doente, atitudes da equipe de enfermagem, bem como as estratégias implementadas pelo cuidador familiar que lhe possibilitam, dentro de sua experiência, dispensar os serviços de enfermagem domiciliar. Ela se compõe de cinco el ementos denominados por nós, como: a) enfrentando o medo do desconhecido; b) aprendendo a vencer as barreiras do desconhecido com ajuda da enfermagem; c) não se sentindo confortável, convivendo com a enfermagem no domicílio; d) vendo que o doente não precisava mais de cuidados de enfermagem; e) dispensando os cuidados de enfermagem.

No enfrentamento do desconhecido, ao cuidar de uma pessoa com AVC, o cuidador familiar decide chamar o problema para sua responsabilidade. Isto faz com que ele passe a lidar com situações sobre as quais não tem domínio, o que, conseqüentemente, o faz conviver com incertezas e perigos ao cuidar do doente.

Para vencêlos, ele se serve dos conhecimentos da enfermagem, o que Ihe conferirá segurança em lidar com as situações futuras, relacionadas ao seu processo de cuidar.

Tendo rompido as barreiras do desconhecido e não se sentindo confortável com a enfermagem no domicílio, mediante a recuperação do doente ele percebe que não precisará mais contar com serviços especializados. Assim o cuidador acaba dispensando a enfermagem e contratando apenas um acompanhante para o doente.

A experiência do cuidador familiar mostra o não-desenvolvimento de um relacionamento terapêutico com a equipe de enfermagem, quando encontra dificuldades no estabelecimento de uma relação de confiança. Ao percebê-las, surgem outros problemas, além daqueles todos que já possui, como: a) perdendo a tranqüilidade com a alta rotatividade da equipe; $b$ ) convivendo com enredos e intrigas entre os elementos da equipe de enfermagem.

... nem sabia que poderia existir esse problema. N unca conheci ninguém. $\mathrm{N}$ em pensava que uma pessoa pudesse ficar em estado vegetativo ... 
... mas aí eu comecei a ver ... que não adiantava ficar melastimando. Então eu achei melhor fazer ao contrário. Parar de me lastimar e cuidar e éo que deu certo ...

... a fase pior que era quando ele estava com a sonda enteral edepois passou para sonda nasogástrica. Era o perigo de entupimento e de ele retirar esta sonda, 0 que aconteceu por várias vezes ...

... de repente eu via a coisa acontecer na minha casa eeu tive que nadar de braçada num mar desconhecido, contra a correnteza para aprender a me virar ...

... ele, também, é uma pessoa que agora não precisa mais de cuidados de enfermagem, porque ele não toma medicamento nenhum. Então, ele não precisa dos cuidados fora os normais: ter uma boa alimentação e ter uma boa higiene...

... eu fui aprendendo muito bem como funcionava tudo isso. Com a ajuda das enfermeiras ... fui aprendendo bastante coisa e dispensei todas. Não tive mais enfermeiras. Tenho sim, uma pessoa que ajuda a fazer companhia ...

\section{Não vendo perspectivas de melhora do doente}

É uma categoria que exprime uma segunda possibilidade na experiência do cuidador familiar, quando, avaliando os resultados de seu modo de cuidar, acaba não enxergando possibilidades de o doente recuperar sua autonomia.

... Quando fez quatro semanas. Eles mesmos não sabiam mais o que falar. Aí neste estado, ela está até hoje...

\section{- Perdendo a esperança de reconquistar a liberdade}

É uma categoria que exprime o momento em que o cuidador familiar avalia a sua experiência e, conseqüentemente, acaba percebendo as possibilidades esgotadas, após experimentar algumas estratégias que pudessem Ihe garantir a liberdade. Esta categoria agrupa três subcategorias: a) sentindo-se decepcionado com a não-recuperação do doente a tratamentos prometedores; b) tendo a proposta de se livrar do papel de cuidador inviabilizada pela família; c) tendo medo de perder o suporte da enfermagem, mantido por convênio.

Sentindo-se decepcionado com a não-recuperação do doente a tratamentos prometedores. Significa que o cuidador familiar se vê desiludido e enganado, quando não vê melhora no doente, após ter depositado sua confiança e es- perança em tratamentos com os quais o profissional promete resultados positivos na recuperação do indivíduo. Esta subcategoria congrega os elementos: a) acreditando na recuperação, mediante promessa de tratamento eficaz; $b$ ) sentindo-se decepcionado com a não-efetividade do tratamento.

... aí passados sete meses foi colocada uma válvula encefálica e o pior que o médico disse que ela poderia andar e falar depois que colocasse a válvula. Essa foi a maior decepção, porque el esabia que não ia acontecer isso. Ela passou mal, deu outro derrame e ela saiu como ela está até hoje... (1)

Tendo a proposta de se livrar do papel de cuidador inviabilizada pela família. Significa que, estando diante de um doente sem possibilidades de recuperação de sua autonomia, o cuidador vê negado, pela família, um plano arquitetado por ele para se livrar do papel.

... eu gostaria que meu filho se casasse novamente, com uma mulher livre e de sua idade. Assim, ela poderia vir morar aqui e assumir o cuidado da L., que apesar dos médicos falarem que ela não tem nenhuma comunicação com o mundo externo, el e teme que ela entenda que existe outra pessoa na vida dele e na própria casa. Ele prefere respeitar o espaço da mulher e manter um caso fora do casamento ...

Tendo medo de perder o suporte da enfermagem, mantido por convênio. É uma reação desencadeada naquele cuidador familiar que já não consegue vislumbrar a melhora do doente ou qualquer outra possibilidade de se tornar livre dentro do papel assumido. Perante a situação, ele passa a conviver com o temor de que, em algum momento da experiência, ele possa vir a perder 0 apoio da enfermagem domiciliar, mantida por convênio médico. Este é que possibilita oferecer toda a assistência de que 0 doente necessita, e, por sua vez, o cuidador familiar sabe que sem el e não poderia custear a enfermagem e todo o tratamento, o que poderia tornar sua situação pior, dentro da possibilidade de ter que assumir o cuidado, sem suporte, de uma pessoa totalmente dependente.

... se não fosse o convênio, não teria ninguém, nem que vendesse tudo o que tinha, até o fogão, não daria para cuidar do jeito que ela foi cuidada. Até quando agüentar, porque tudo hoje eles cortam. Por enquanto não. O s relatórios eram de seis em seis meses para renovar, agora o convênio passou para três. Então a gente fica com medo quando começa a diminuir ... você vê tem enfermagem 24 horas... 


\section{Não estimulando a autonomia do doente}

É um segundo modo de cuidar, quando o cuidador familiar acredita que, ao assumir o papel, deve fazer tudo pelo doente, desconsiderando-o como sujeito ativo e participativo de sua recuperação. Esta categoria congrega duas subcategorias: a) superprotegendo 0 doente; b) sendo resistente em estimular o doente $a$ andar.

Superprotegendo o doente. Significa um conjunto de atitudes do cuidador familiar, de maneira a fazer tudo pelo doente, desconsiderando-o como sujeito participativo e ativo de sua recuperação.

... atéa fisioterapeuta fala para mim: - Ah! Se a M . (irmã) tivesse sido assim desde o começo com ela. Ela talvez não precisasse de mais ninguém para ajudá-la a andar, mas ela foi muito paparicada no começo. Então ela mal acostumou ...

Sendo resistente em estimular o doente a andar. É uma atitude característica do cuidador familiar superprotetor que, mesmo estando orientado por profissionais e outros elementos da família da necessidade de incentivar o doente a realizar suas atividades por si só, respeitando o nível de dependência do mesmo, age ao contrário, fazendo tudo pelo doente, considerando-o um agente passivo no tratamento e não estimulando o indivíduo a se esforçar e tentar desenvolver habilidades importantes para a recuperação de sua autonomia.

... a minha irmã colocava muito naquela cadeira. Qualquer coisinha colocava na cadeira. Então eu falei: - Se você continuar colocando ela toda hora na cadeira, ela não vai andar nunca. Você tem que forçar ela a andar ...

\section{Promovendo a dependência do doente}

É o resultado da avaliação feita pelo cuidador familiar ao vivenciar seu próprio modo de cuidar de um indivíduo com AVC, quando este é desconsiderado como ser participativo e ativo de seu processo de recuperação. Ele percebe, com o desenvolvimento de sua experiência, que não está contribuindo com a independência dos seus cuidados ao superproteger 0 doente. Esta categoria reúne as subcategorias: a) desenvolvendo uma relação de dependência recíproca doente-cuidador familiar; b) tornando-se 0 doente cada vez mais dependente da família; c) retardando o processo de reabilitação do doente.

D esenvolvendo uma relação de dependência recíproca doente-cuidador familiar. Significa que na experiência em que o cuidador familiar não conta com uma pessoa de fora do círculo familiar, como suporte nos cuidados, há uma possibilidade maior de se desenvolver uma relação de servidão entre os sujeitos, interferindo no processo de independência de ambos, o que seria mais difícil acontecer quando contando com cuidadores de fora.

... a pessoa doente que fica sendo cuidada só pelos familiares ... fica muito dependente da família ...

... eu dependo muito mais dele, porque se acontecer alguma coisa comigo, ele terá quem me substitua, ao passo que se acontecer alguma coisa com ele, eu vou ficar em desespero, porque eu preciso muito mais dele... Ele é uma pessoa que não vejo a hora que ele acorde. Ele está dormindo e você vê. Quantas vezes que eu olhei para lá. Eu quero que ele descanse, mas é para eu conversar eficar junto dele...

Tornando-se o doente cada vez mais dependente do cuidador familiar. É uma conseqüência de atitudes superprotetoras adotadas por aquele cuidador que não estimula a autonomia do doente, podendo até aumentar o nível de dependência deste.

... então ela não faz nada por si. É tudo a gente quetem que fazer. Ela écompletamente dependente das pessoas...

... ela foi paparicada no começo ... Agora ela acha que a gente tem que fazer tudo por ela. Ela não quer fazer nada ...

Retardando o processo de reabilitação do doente. É o resultado percebido pelo cuidador familiar ao avaliar o seu modo de cuidar. Ele evidencia que, não estimulando a autonomia do doente, acaba comprometendo o seu processo de reabilitação.

... ela depende de tudo da gente. Ela não faz nada sozinha .. Ela começou a andar um pouco agora. Depois de quase dois anos, ela começou a se movimentar, mas com ajuda da gente...

\section{Sentindo-se preso ao doente dependente de cuidado domiciliar}

Significa que as atitudes superprotetoras adotadas pela família ao cuidar do doente não promovem a independência deste e, conseqüentemente, diminuem as perspectivas de o cuidador familiar readquirir sua liberdade do processo assistencial circunscrito à casa. A autonomia do doente significa a independência do cuidador familiar.

... as pessoas doentes que ficam sendo cuidadas só pelos familiares ... ficam muito dependen- 
tes da família e ... acham que a família tem que se desdobrar só para ela ... Elas acham que você tem que se anular, tem que só viver para ela. Vocênão pode fazer mais nada ...

... é difícil, porque tem que levar para o banheiro. Tem que dar banho. Tem que dar remédios na hora certa ... Todo dia tem que ficar à disposição aqui dentro de casa ...

\section{Analisando e discutindo a experiência}

Ao inter-relacionar os componentes (categorias, subcategorias e elementos) relativos à temática desenvolvendo seu modo de cuidar, buscando compará-los e analisá-los para compreender como se dava a interação entre eles, percebemos que, no processo interacional cuidador familiar-pessoa com AVC, a autonomia também é compartilhada. 0 próprio cuidador familiar percebe que o processo de retomada da autonomia, tanto a da pessoa vitimada pelo AVC quanto a sua, se configura como interdependente e condicionado ao nível de reabilitação alcançado pelo doente.

Com o tempo, assumir o papel de cuidador de pessoa com AVC traz poucas satisfações ao familiar. Com isso a adoção de um modo de cuidar acaba sendo muitas vezes a única opção para ambos recuperarem as suas independências.

A experiência demonstra que uma das condições para o familiar se libertar ou não do papel está condicionada à recuperação da autonomia do doente e que esta, por sua vez, pode estar relacionada à modalidade de cuidado adotado pelo cuidador. A escolha por uma modalidade que não estimula a autonomia do doente também promove a reclusão do cuidador, distanciando-o do vir-a-ser livre de um papel que não Ihe traz satisfações. As estratégias que superprotegem não promovem a autonomia da pessoa com incapacidades, ao se estabelecer uma relação de dependência recíproca doente-cuidador familiar, tornando 0 primeiro cada vez mais dependente da família e, conseqüentemente, retardando o processo de reabilitação. M ediante o processo empreendido, ele acaba promovendo a relação de dependência e, conseqüentemente, preso a sua própria escolha de modalidade de cuidados.

De acordo com Farzan (1991), as atitudes dificultadoras no processo de reabilitação são as de cunho paternalista, impedindo o sobrevivente do AVC em fazer o que é capaz, conduzindo-o à regressão e à perda da auto-estima, bem como aquelas que consideram a doença precursora de morte e as incapacidades geradas por ela desesperadoras. Estas atitudes acabam desempenhando um papel desmotivador na recuperação.

Por outro lado, segundo Bocchi (2001), a adoção da modalidade incentivando 0 doente a recuperar a sua autonomia é uma das possi bilidades de se livrar do papel e retornar ao seu plano de vida, principalmente quando o cuidador não pode contar com outra pessoa com quem divida o trabalho ou o assuma. É um modo de o cuidador familiar se integrar ao processo de reabilitação do indivíduo, considerando-o sujeito participativo e ativo de sua recuperação. Ele vai estimulando o restabelecimento de movimentos, reorientando o doente no tempo e no espaço e oferecendo outros cuidados que 0 ajudam na recuperação. Conseqüentemente, ele vai percebendo a recuperação da autonomia do doente, ao vê-lo se tornando funcionalmente independente e recuperando, gradativamente, a consciência. Estas evidências, conseqüentemente, nutrem suas expectativas da reconquista da liberdade do papel.

Para Farzan (1991), a família de suporte é aquela que desempenha um papel de facilitadora durante a reabilitação. Ela é positiva em suas atitudes e interações com o paciente. Considera o mérito da pessoa, incluindo-a na tomada de decisões e permitindo-Ihe participar e contribuir em papéis importantes no seio familiar, sempre respeitando suas habilidades para a função.

Segundo Tognola (1996), o processo de recuperação não depende somente da terapia, mas também da relação com a severidade da lesão cerebral. 0 estudo de Barros (1991) mostra que, em longo prazo, $48 \%$ dos sobreviventes com AVC não conseguirão se autocuidar, sendo que $16 \%$ deles com incapacidade moderada, capazes de andar sem ajuda, necessitam de alguma ajuda para se vestir. E que $32 \%$ com incapacidade moderadamente intensa ou grave requerem a ajuda tanto para andar quanto para se cuidar ou se encontram totalmente restritos ao leito ou a uma cadeira de rodas, geralmente com incontinências esfincterianas e totalmente dependentes de cuidados. Somente $15 \%$ se tornarão livres de qualquer grau de incapacidade e 37\%, com discreta incapacidade, não podem desenvolver algumas atividades, que previamente exerciam, mas são capazes de se autocuidar.

$N$ esses casos o familiar acaba perdendo a esperança de recobrar a sua liberdade do papel, 
ao não vislumbrar a melhora do doente, mesmo adotando uma modalidade fundamentada em atitudes de incentivo à recuperação da autonomia.

0 trabalho de Bocchi (2001) evidencia que, quando o cuidador familiar vê esgotadas as suas possibilidades de se livrar do papel, por meio de ações que visem à recuperação ou em contar com uma companhia para o doente, pode adotar duas direções: acomodando-se à situação de cuidador ou retomando as estratégias que possam torná-lo livre.

Para a autora, acomodando-se à situação significa que o cuidador familiar decide continuar desempenhando o seu papel junto do doente. A pesar da sobrecarga que esse pode proporcionar a sua vida, ele procura ir superando ou convivendo com os problemas com resignação e, principalmente, em consideração ao doente.

Por outro lado, acrescenta que as ações do familiar podem se mover no sentido de se tornar livre do papel, visando à busca de outro cuidador, por meio de duas estratégias: - tentando vencer as dificuldades de contratação; forçando a busca de uma outra pessoa.

Para Bocchi (2001), tentando vencer as dificuldades de contratação de um cuidador significa que o familiar retoma suas estratégias, anteriormente abandonadas, para tentar resolver problemas relacionados à contratação de uma pessoa, para que esta venha assumir, integralmente, a assistência do doente. Ademais, ele pode se servir da outra estratégia que seria a busca de outro cuidador; no entanto, isto pode provocar um estado de sofrimento no doente, mediante atitudes de desconsideração com a pessoa, de forma que ela venha exteriorizar seus sentimentos. Com isto, ele atinge a sua meta ao tornar visível para as outras pessoas da casa que, talvez, o paciente ficasse melhor com outra pessoa e, sensibilizados com a situação, se mobilizariam para encontrar um outro cuidador.

Essas ações podem ser explicadas por meio do Interacionismo Simbólico, segundo Charon (1989), ao considerar que as ações são causadas por um processo ativo de tomada de decisão pelo sujeito que envolve a definição da situação e esta, por sua vez, envolve interação consigo mesmo e com os outros. Dessa forma, a definição da situação feita pelo ator é central para determinar como ocorrerá a ação.

De acordo com Dorsey \& Vaca (1998), embora as perspectivas para o sobrevivente de AVC sejam mais promissoras que anteriormente, a necessidade por reabilitação continua envolvendo pacientes e familiares. U ma atmosfera encorajadora e de suporte para o cuidador e 0 seu entendimento sobre as mudanças físicas e emocionais da pessoa com AVC são determinantes essenciais para uma reabilitação bemsucedida, após a alta hospitalar. 0 envolvimento da família no cuidado e a provisão de educação sobre a recuperação após AVC contribuem para uma melhor qualidade de vida, tanto para o paciente quanto para os familiares.

Enfatizam Cassidy \& Gray (1991) que somente os serviços de suporte hospitalar e domiciliar oferecidos a pessoas na fase aguda do AVC não são suficientes para reduzir o estresse dos cuidadores em longo prazo. Isto denota que as intervenções não devem se restringir apenas ao período agudo, mas serem reforçadas durante o período de recuperação.

Acerca da sobrecarga gerada pelo papel de cuidador de pessoa com AVC, Bocchi (2004) divulga o conhecimento a partir das pesquisas sobre a temática, publicadas em periódicos nas décadas de 1980 e 1990.

A autora acredita que o conhecimento apresentado acerca das conseqüências psicossociais sobre cuidadores familiares de pessoas com AVC possa se constituir, também, em um referencial à equipe de saúde na elaboração de intervenções direcionadas às famílias afetadas por tal experiência, como estratégia de melhoria da qualidade de vida.

\section{Tecendo as considerações finais}

Este artigo apresentou os modos de cuidado, bem como o movimento empreendido como parte do modelo teórico M ovendo-se entre a liberdade e a reclusão: vivendo uma experiência de poucos prazeres ao vir-a-ser um cuidador familiar de pessoa com AVC.

Entendemos que o modelo se constitui em um referencial teórico para ajudar a equipe de saúde a avaliar a interação da família no processo de reabilitação domiciliar da pessoa com AVC. Para isso é imprescindível compreender como o familiar define a situação vivenciada, tentando antever qual a direção que está adotando ou, provavelmente, adotará perante o processo de reabilitação.

Este modelo poderá, também, servir como um conteúdo de ensino para os cuidadores, de maneira a fazê los compreender que o modo de 
cuidar escolhido pela família é um dos caminhos que pode não só beneficiar os pacientes, mas a própria retomada da autonomia do cuidador, obviamente, sem deixar de enfatizar que o processo de reabilitação/readaptação visa à reintegração do paciente ao convívio social. Meta difícil de ser alcançada por ser uma lesão que limita a autonomia do indivíduo eque, por sua vez, necessitará que a família adote atitudes facilitadoras na reintegração do sujeito. 0 objetivo final, de qualquer modo, é obter a melhor qualidade de vida possível para aquele indivíduo. Assim, não pode ser esquecido, no contínuo do tratamento, que a recuperação é mais acelerada nas primeiras semanas e é difícil dizer o ponto em que ela cessa.
É por estas razões que se torna imprescindível 0 acesso do binômio cuidador familiar-pessoa dependente às Políticas Públicas de Saúde que promovam programas de avaliação e de intervenções implementadas, continuadamente, por equipes de saúde. Trata-se de um papel que gera sobrecarga com relação àqueles que cuidam de pacientes que não apresentam um quadro promissor de recuperação da autonomia e, principalmente, desprovidos de suporte social efetivo. Ressaltamos que, provavelmente, estes terão a saúde física e mental expostas aos efeitos de assumir o papel de cuidador familiar, podendo comprometer o processo de reabilitação/readaptação do paciente e até empreenderem ações extremas de submissão do doente a maus-tratos.

\section{Colaboradores}

SCM Bocchi foi a responsável pela elaboração e execução do projeto de pesquisa, bem como pela formatação do artigo. M Angelo orientou a elaboração e a execução do projeto de pesquisa e a formatação do artigo.

\section{Agradecimentos}

Este artigo é parte da tese de doutorado M ovendo-se entre a liberdade e a reclusão: vivendo uma experiência de poucos prazeres ao vir-a-ser um familiar cuidador de uma pessoa com AVC, subsidiada pelo CN Pq e orientada pela professora titular M argareth Angelo. 


\section{Referências bibliográficas}

Barros JEF 1991. Acidente vascular cerebral, pp. 133-147. In R Nitrini \& LA Bacheschi (orgs.). A neurologia que todo médico deve saber. M altese, São Paulo.

Bocchi SCM 2001. M ovendo-se entre a liberdade e a re clusão: vivendo uma experiência de poucos prazeres ao vir-a-ser um cuidador familiar de uma pessoa com AVC. Tese de doutorado. Universidade de São Paulo, Escola de Enfermagem, São Paulo.

Bocchi SCM 2004. Vivenciando a sobrecarga ao vir-a-ser um cuidador familiar de pessoa com acidente vascular cerebral (AVC): análise do conhecimento. Revista Latino-Americana de Enfermagem 12(1):115-121.

Cassidy TP \& Gray CS 1991. Stroke and the carer. British Journal of General Practice 41(348):267-8.

Charon JM 1989. Symbolic interactionism: an introduction, an interpretation, an integration. Prentice $\mathrm{H}$ all, Nova York.

Dorsey M K \& Vaca KJ 1998. The stroke patient and assessment of caregiver needs. Journal Vascular N ursing 16(3):62-7.

Ellekjaer H, Holmen J, Indredavik B \& Terent A 1997. Epidemiology of stroke in Innherred, N orway, 1994 to 1996: incidence and 30-day case-fatality rate. Stroke 28(11):2180-2184.

Farzan DT 1991. Reintegration for stroke survivor: home and community considerations. The N ursing Clinical of $\mathrm{N}$ orth America 26(4):1037-48.

Glaser BG \& Strauss AL 1967. The discovery of grounded theory. Aldine, Nova York.
Grant JS 1996. Home care problems experienced by stroke survivors and their family caregivers. Home H ealthcare N urse 14(11):892-902.

Griffin JQ 1980. Physical illness in the family, pp. 246268. In R Miller, EH Janosik. Family-focused care. McGraw Hill, Nova York.

M auss-Clum N, Ryan M 1981. Brain injury and the family. Journal of N eurosurgical Nursing 13(4):165-169.

M inistério da Saúde 2000. Programas e projetos: doenças cardiovasculares. Disponível em <http://www.saude. gov.br>.

Ragland DR, Buffler PA, Reingold AL, Syme SL, Buffler ML 1998. Disease and injury in California with projections to the year 2007: implications for medical education. Western Journal of M edicine 168(5):378399.

Reeber BJ 1992. Evaluating the effects of a family education intervention. Reabilitation N ursing 17(6):336-340.

Reitsma JB, Limburg M, Kleijnen J, Bonsel GJ, Tijssen JG 1998. Epidemiology of stroke in the Netherlands from 1972 to 1994: the end of the decline in stroke mortality. N euroepidemiology 17(3):121-131.

Tognola WA 1996. Qualidade de vida após o acidente vascular encefálico, pp. 437-48. In RJ Gagliardi (ed.) D oenças cerebrovasculares:condutas. Geo-Gráfica e Editora, São Paulo.

Youngblood N M , Hines] 1992. The influence of the family's perception of disability on rehabilitation outcomes. Reabilitation N ursing 17(6):323-326.

Artigo apresentado em 25/10/2004

Aprovado em 25/01/2005

Versão final apresentada em 25/01/2005 